\title{
Innovatieve 'index-linked' beleggingsinstrumenten
}

\author{
Dis. P.J.W. Duffhues
}

\section{Inleidling}

Nederland lijkt. in navolging van de Angelsaksische landen, in de tweede helft van de jaren negentig rijp voor een innovatieve golf van beleggingsproducten. Een gunstige conjuncturele en structurele economische ont wikkeling, hoge belastingtarieven voor particuliere beleggers. lage rentetarieven op de geldmarkt en een toegenomen financiële creativiteit hebben in het begin van de jaren negentig reeds geleid tot verhoogde belangstelling voor directe en indirecte beleggingen op de aandelenmarkt. Nadat in 1995 het gemiddeld koerspeil op de aandelenmarkt in Amsterdam zeer sterk was gestegen. en de mogejijkheid van een omslag niel langer als een theoretische 'optie' kon worden alfgedaan, ontstond logischerwijze een behoefte aan beschermende producten in de sfeer van aandelenbeleggingen. Deze stap werd in Nederland in 1995 gezet met de introductie van onder andere de Centraal Beheer alandelenindexpolis en het beleggingsinstrument 'Escape van bank Bangert Pontier N.V. te Amsterdam. Later volgden vele andere nieuwe financiële producten onder vele namen. Zo werden ook zogenaamde 'click'-fondsen gelanceerd die hun naam ontieenden aan het feit dat aan de deelnemers dank zij bepaalde ingebouwde financiële mechanismen zekerheid werd geboden dat een eenmalal behaald. vooraf gedefinieerd, hoger koersniveau niet meer verloren kon gaan door latere koersontwikkelingen. Om fïscale redenen werd bij de later bedachte

Drs. P.J.W. Duffhues is hoofddocent vakgroep Bedrijfseconomie (sectie Ondernemingsfinanciering) en Director of Studies aan het TIAS aan de Katholieke Universiteit Brabant. beleggingsproducten een beperkt "eigen risico" ingebouwd van ongeveer $7 \%$ hetgeen voor de fiscale overheid blijkbalar aanvaardbaar was gebleken in besprekingen die met belanghebbenden die op fiscaal vrije koerswinsten mikten. hadden plaatsgevonden.

"Escape" is vergeleken met de aandelenindexpolis van centraal Beheer een simpeter product. Het is "slechts" een beleggingsproduct, geen bijproduct van een verzekering. De volle inleg van de belegger wordt gegarandeerd terugbetaald aan het einde van een periode van vijf jaar. Als de AEX op 28 december 2000 hoger staat dan op 28 december 1995 ontvangt de belegger het hogere bedrag dat door de index wordt iangegeven.

De toegenomen concurrentie onder de financiële intermediairs maikt hel aantrekkelijk. zelfs noodzakelijk om vernieuwend bezig te zijn in de $\mathrm{kwaliteit}$ van de beleggingsdienstverlening. Dit stemt ook overeen met de theorie over het ontstaan van fïnanciële innovaties in de financieringsliteratuur. De neiging om particuliere beleggers te bewegen tol investeren in florerende aandelenmarkten is slechts toe te juichen. Anderzijds rijst de vraag welke toegevoegde waarde de nieuwe financiële instrumenten bezitten voor de koper. Valak worden nieuwe financierings- en beleggingsinstrumenten beoordeeld als combinaties van bestaande instrumenten zodal er reëel gezien geen nieuws onder de zon is. De vraag is of dat het complete verhaal is.

Het doel van dit artikel is tweeledig. Allereerst wordt in het kort (paragralal 2) de essentic van zo' $n$ nieuw beleggingsproduct beschreven walarbij bijzondere aandacht zal uitgaan naar de Escape 
als een van de aandacht trekkende vernieuwingen in Nederland. Vervolgens wordt (in paragraaf 3) de belangrijkere vraag aan de orde gesteld welke toegevoegde waarde dergelijke garantieproducten bezitten. In paragraaf 4 volgt een samenvatting.

\section{De 'Escape'}

Een 'Escape' is uiterlijk gezien een betrekkelijk eenvoudige beleggingsvorm die neerkomt op een belegging in de aandelenindex van de beurs zonder recht op dividend en die is afgedekt met een putoptie. De premie voor de putoptie met als uitoefeningsprijs de beginstand van de index voor een looptijd van 5 jaar wordt 'betaald" door af te zien van dividenden op de onderliggende waarden. Deze premie kan achteraf volledig verloren zijn.

Kader 1 bevat voor de geïnteresseerde lezer enkele meer technische details van de Escape.

\section{Kader 1}

De term Escape is een afkorting van Equity Structured Call and Put Exposure. Hieruit blijkt dat het om het risicoprofiel van een belegging in de aandelenmarkt gaat en dat dit profiel een complex karakter draagt ('gestructureerd' staat in dit kader voor 'opgetuigd met toeters en bellen'); de beoogde structuur wordt verkregen met een combinatie van een call en een put positie. Escape is zelf een optie, en wel een call optie.

De optie 'Escape' is een recht om twee andere optiestructuren te kopen: een call spread warrant èn een put spread warrant, beide met de Amsterdam EOEindex $(=\mathrm{AEX})$ als onderliggende waarde. Deze twee warrants zijn uitgegeven door Midland Bank plc in Engeland en verhandelbaar op de Londense beurs. De term 'spread' duidt in dit geval op een verandering van de aandelenindex.'

Worden de Escapes tijdens de looptijd niet uitgeoefend, dan vindt automatisch uitoefening van het kooprecht plaats op de laatste handelsdag: als pakket hebben ze immers altijd waarde omdat de gegarandeerde waarde positief is.

De Escape is vanaf 8 januari 1996 tot het einde van zijn looptijd dagelijks verhandelbaar op de afdeling 'special products' van de Amsterdamse optiebeurs. De beleggers in Escape kunnen dus tussentijds profiteren van een gestegen koersniveau zonder gevangen te zijn in een verplicht houderschap van de belegging tot 2001.

De waarde van de call spread warrant neemt versneld toe zodra deze intrinsieke waarde krijgt. Het profiel van de call spread warrant toont een geknikt verloop (OABC in figuur A). Het gaat om het recht om bij expiratie tien keer het verschil te ontvangen tussen twee maxima die elk ten minste nul zijn.
Figur A: De pay out van de call spread warrant bij expiratie in het jaar 2000

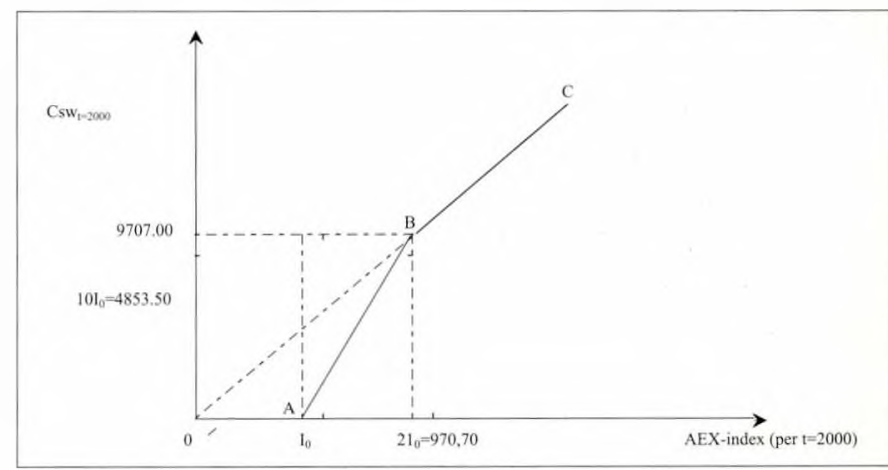

De waarde van de put spread warrant daalt als de call spread warrant intrinsieke waarde krijgt (DEF in figuur $\mathrm{B}$ ) maar blijft positief totdat de index is verdubbeld.

Figuur B: De pay out van de put spread warrant bij expiratie in het jaar 2000

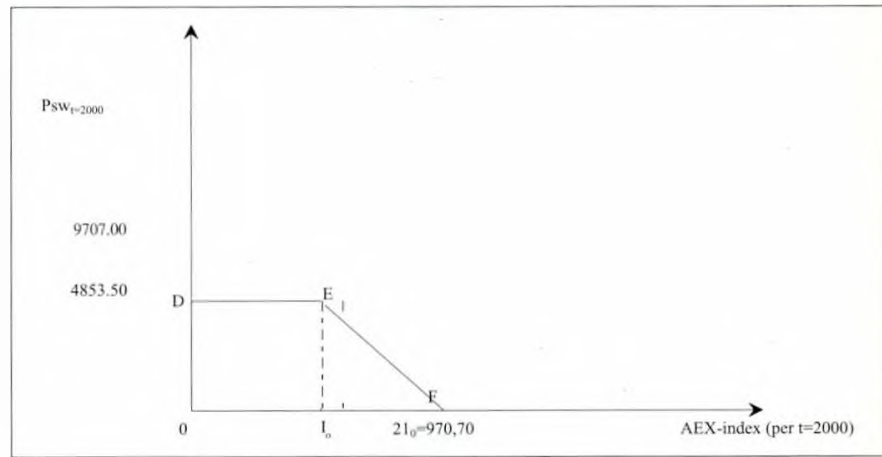

Beide warrants bezitten verrassend lang een positieve intrinsieke waarde en zullen dus nog worden uitgeoefend zelfs als de index sterk (maar met minder dan 100\%) gestegen is.

De nakoming van de verplichtingen uit hoofde van de afrekening op de warrants schept voor de houder van de Escape een kredietrisico op Midland Bank plc. 
Figuur 1 bevat het eindresultaat als combinatie van de figuren A en B uit kader 1.

De Escape is immers de portefeuille van de twee spread warrants. In totaal gezien neemt de waarde van de combinatie precies gelijk toe met de index (45"-lijn) althans vanaf het moment dat de Escape intrinsieke waarde krijgt. Daarbeneden ligt de waarde bevroren. Dat is wat de initiatiefnemers in het prospectus in het vooruitzicht stellen (DEBC).

Figun 1: De pay out van de Escape bij expiratic in het jaar 2000

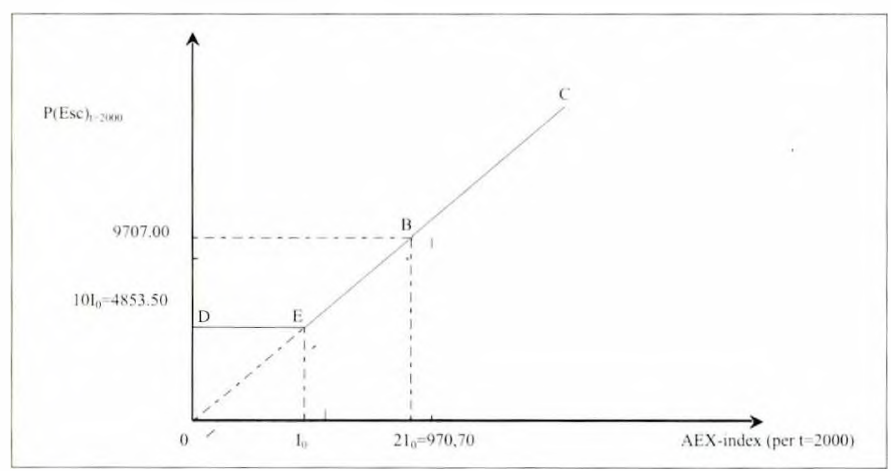

Uit figuur I blijkı dat de Escape inderdaad een relatief veilige optie is: het is een vernuftig geconstrueerde synthetische call optie op de AEXindex in combinatie met een risicovrije belegging op het niveau D. Uit het complexe geheel van de werking van twee warrants ontstaat het eindbeeld dat men minimaal de inleg van de investering terugontvangt. Stijging van de index boven het beginniveau verlaalt zich uiteindelijk in een zelfde waardestijging van de Escape (verloop DEBC). Voor de praktisch georiënteerde beleggers is alleen figuur I van belang omdat die het (eind)resultaat van een op zichzelf gezien ingewikkeld product weergeeft.

\subsection{Escape-risico"s}

De volgende risico's moeten worden onderkend bij belegging in Escape.

\section{Marktrisico l'an de index}

In de eerste plaats biedt de Escape cen econoninisch risico omdat de toekomstige positie op de lijn DEBC in figuur I vooraf volstrekı onbekend is en niet gecorrigeerd is voor inflatie.

\section{Marktrisico l'an de optie}

Daarnaast kan de impliciet betaalde premie voor de bescherming van de inleg (niveau D) achteraf waardeloos blijken te zijn. Deze premie wordt op een bijzondere wijze in rekening gebracht. Het is de contante waarde van de reeks van dividenden over de in de index opgenomen aandelen die de Escapebezitter niet ontvangt.

\section{Kredietwardigheidsrisico}

Het is evident dat wanneer Midland Bank plc niet aan haar betalingsverplichtingen eind 2000 voldoet, de Escape-belegger alle negatieve gevolgen daarvan zal ondervinden. Bij de bemiddelende Amsterdamse bankier is in deze geen enkele aansprakelijkheid neergelegd.

\subsection{Fiscal risico}

De fiscale autoriteiten hebben aanvankelijk aan de bank Bangert Pontier N.V. duidelijk gemalakt dat vermogenswinsten op de Escape bij particulieren zullen worden belast met inkomstenbelasting omdat het hier zou gaan om een spaarproduct waarop fiscaal gezien rente wordt verdiend. Om meerdere redenen is dit echter aanvechtbaar.

Op de eerste plaats hebben we hierboven reeds aangetoond dat er ten minste twee zeer reële economische risico's kleven aan de Escape. Daarnaast is er een kredietwaardigheidsrisico. In de tweede plaits zou belastingheffing over de Escape-winsten moeten leiden tot heffing over winsten op andere vergelijkbare producten en constructies met derivaten (zoals aandelenswaps en aandelenfutures) die voorzover bekend niet ter discussie staan. Hendriks heeft onlangs een overzicht gegeven van de verschillende wegen die tot hetzelfde aandelenrisicoprofiel leiden (Hendriks. 1995). Het probleem is nu blijkbaar dat de fiscus deze samenhangen (nog) niet erkent. $\mathrm{Zij}$ heft wel volgens de ene benadering (linksom), niet volgens een andere benadering ('rechtsom'). Dat kan niet als de producten identiek zijn. ${ }^{2}$

\subsection{Conclusie}

De Escape is een innovatief beleggingsinstrument voor de Nederlandse aandelenmarkt. Het is een complex instrument omdat het een optie is op twee onderliggende optiestructuren. Deze laatste geven als pakket bij expiratie in het jaar 2000 recht op een waarde die gelijk is aan tenminste de 
inleg van de Escape op 28 december 1995. De

Escape is imiteerbaar bijvoorbeeld door zelf in de marktportefeuille te beleggen en daaraan een meerjarige putoptie toe te voegen. De Escape kost eenmalig een bedrag aan transactiekosten; de hoogte hiervan is echter afhankelijk van de in te voeren veronderstellingen onder andere terzake van de toekomstige dividenden op de marktportefeuille en de volatiliteit van het rendement op de index. De Escape brengt een aantal risico's met zich mee (marktrisico onderliggende waarde en optie, kredietwaardigheidsrisico). Vermogenswinst uit de Escape kan in redelijkheid niet worden belast met inkomstenbelasting omdat dit een discriminerende behandeling zou opleveren van economisch vergelijkbare producten (gaat men 'rechtsom' of 'linksom'). De gesommeerde contante waarde van de in vijf jaar in de Escapeconstructie te derven dividendrendementen kan worden gezien als de geïnvesteerde putpremie voor een 5 -jaarsoptie.

Kijken wij nu naar de bestaansgrond van dergelijke producten vanuit de theorie.

\section{De toegevoegde waarde}

De Escape en vele andere nieuwe financiële instrumenten zijn uitingen van 'financial engineering'. Dit is het proces waarlangs nieuwe instrumenten, markten en instituten op maat worden bedacht en gecreëerd met het doel daarmee eindgebruikers een 'economische' dienst te bewijzen. Zonder deze 'economie' geen beloning, en zonder beloning geen intermediair die zich zet aan financial engineering. De vraag is dus wat is de economie of, zo men wil, wat is de toegevoegde waarde van de keur van nieuwe beleggingsproducten waarvan Escape er slechts een is?

\section{I Klassieke benadering}

In een strikt klassieke op gangbare waarderingsmodellen van marktevenwicht gebaseerde 'academische' benadering is het antwoord op de vraag naar de toegevoegde waarde van de moderne beleggingsproducten eigenlijk heel eenvoudig: deze is nihil. Dit geldt in het bijzonder voor de modellen van de werking van financiële markten waarmee beginnende economiestudenten gewoonlijk worden geconfronteerd in hun opleiding. Deze modellen zijn onder andere gebaseerd op de veronderstelling van marktperfectie, dat wil zeggen, er zijn geen fricties in het economisch proces, hetgeen onder andere inhoudt dat alle beleggers dezelfde informatie bezitten. Als gevolg van de marktperfectieveronderstelling is een aantal problemen (zoals verschillen van informatie; zie beneden) die in de werkelijkheid spelen op het niveau van de kandidaatbelegger, eenvoudig niet aan de orde.

De intermediairs die zich met de ontwikkeling en marketing van deze producten bezighouden, zijn in deze klassieke benadering strikt genomen niets anders dan een verzameling verspillers van schaarse middelen. Doordat de producten in dit model geen bestaansrecht hebben, is de impliciete beschuldiging dat hun activiteit tot verstoring van de werking van de financiële markten en tot extra beweeglijkheid van het koerspeil kan leiden. Het hier beschreven oordeel over de intermediair komt overeen met het oordeel dat over banken in het algemeen wordt geveld in het klassieke model. In de economische literatuur is dan ook duchtig gediscussieerd over de vraag waarom er banken en andere financiële instellingen zijn. Dezelfde vraag houdt ons hier bezig ten aanzien van zich productinnovatief opstellende financiële instellingen.

\subsection{Imperfecties}

Er zijn verschillende imperfecties die de beleggers kunnen doen besluiten om kant-en-klare beleggingsproducten te kopen.

\section{a Besparen op informatiekosten}

Op de eerste plaats gaat het na twintig jaar financiële innovatie op de markten over duidelijk specialistische kennis die vereist is om te kunnen beoordelen welke eigenschappen de markten bezitten en welke de verhandelde producten zijn. Dit kennisvereiste fungeert als een reële barrière voor het betreden van de beleggingsmarkt.

De belegger moet hoge (initiële en volgtijdelijke) informatiekosten maken om het voorbereidende en uitvoerende werk van de intermediair te kunnen overnemen. In het algemeen schrikt men daarvoor om begrijpelijke redenen terug. De opportunitykosten zijn te hoog. De intermediair die dit werk overneemt van de kandidaatbelegger, belast terecht zijn kennis en zijn financieringskosten door in het product. Dit houdt in dat het gaat om een rationele vorm van uitbesteden: men bespaart op zoekkosten. 


\section{$b$ Het behalen van schaalvoordelen en risicoreductie}

Een tweede reden is gelegen in de directe nuttigheid die de intermediair kan afwerpen. De eindgebruiker van het nieuwe product kan profiteren van belangrijke schaalvoordelen en risicoreductie die de intermediair hem door zijn bedrijfsmatige benadering van zijn activiteiten kan bieden. Een voorbeeld is de OTC-markt. Deze vervult bij het vereiste maatwerk rondom complexe beleggingsinstrumenten vaak een belangrijke rol. (Denk aan de speciale onderhandse overeenkomst die bank Bongert/Pontier sloot met de Engelse Midland Bank.) OTC derivatenmarkten zijn wel toegankelijk voor gevestigde intermediairs, maar niet of nauwelijks voor eindgebruikers zoals kleine particuliere beleggers. Een ander voordeel kan zijn gelegen in een voordelige fiscale behandeling van het nieuwe product. Deze tweede reden heeft dus het oog op een hogere brutokasstroom (vóór aftrek van de vergoeding aan de intermediair) die de kandidaatbelegger incasseert door via deskundigen te beleggen. Daarnaast kan de intermediair zijn deskundigheid demonstreren door het creëren van een zekere mate van risicoreductie voor de kandidaatbelegger dank zij een bedrijfsmatige procesgang en - indirect - dank zij het toezicht van de monetaire autoriteiten (gewoonlijk de centrale bank) op het reilen en zeilen van de intermediair. In concurrerende verhoudingen zullen al deze voordelen worden doorgegeven aan de klanten. Vooral de markt- en de operationele risico's kunnen door de intermediair worden beperkt.

\section{c Het besparen op 'sociaal-psychologische kosten'}

De derde reden heeft een sociaal-psychologische achtergrond. Alleen al het feit dat men de optie- of termijnmarkt betreedt, bestempelt vele kleine beleggers in de vrienden- en kennissenkring reeds tot speculant. Aan de basis liggen de bekende vooroordelen op dit gebied. Dit duid ik aan als de sociale kostenfactor. Er is weinig fantasie nodig om te beseffen dat dit argument de kleine belegger in de richting van synthetische producten drijft, vooral wanneer deze als pasklare happen worden gepresenteerd zonder reminiscenties als opties en dergelijke. Slim opgezette marketingcampagnes die het nieuwe product begeleiden, spelen op dit argument in door woordkeuzes als 'gegarandeerde opbrengst', 'zekere eindwaarde'en
'Escape'!. De koper van een Escape kan tijdens de maaltijd aan zijn disgenoten gemakkelijk duidelijk maken dat hij aan een heleboel narigheid is ontsnapt. Dat kan hij niet of veel minder gemakkelijk als hij zegt met een optietransactie bezig te zijn. Academische modellen van het klassieke type houden geen rekening met dit soort kosten.

\section{d Myopische afkeer van verlies}

Uit de literatuur over het kennisnemen van beleggingsverliezen en -winsten is bekend dat de risicoafkeer van beleggers toeneemt naarmate de periode tussen twee evaluaties van de portefeuille kleiner wordt (Vorst, 1995). Dit verschijnsel doet zich waarschijnlijk in relatief sterke mate voor bij de beginnende belegger wanneer deze een overconcentratie aan aandacht voor zijn effectenportefeuille bezit. Doordat hij of zij simpel als uitvloeisel van de inspectiefrequentie van de portefeuille vaker met verliezen wordt geconfronteerd blijkt een sterke risicoafkeer te worden ontwikkeld. Dit psychologisch trekje is aangeduid als 'myopic loss aversion' (Benartzi en Thaler, 1993). Dit soort beleggers is bereid een premie te betalen boven de marktrisicopremie. Het gevolg is dat elk product met een nagenoeg risicoloze minimumopbrengst in goede aarde zal vallen bij deze beleggers. Dit geldt des te sterker naarmate de aandacht voor de performance van de aandelenmarkt hoger is. Dit is het geval met de koersniveaus in de tweede helft van de jaren negentig. Een uitzonderlijk sterke risicoafkeer doet deze beleggers belanden bij in sterke mate beschermende beleggingsproducten. Dat mag dan ook wat kosten.

\section{e Alleen 'downside risk'}

Beleggers proberen in vele gevallen verliezen te vermijden die hen in grote problemen zouden kunnen brengen, mogelijk zelfs een faillissement zouden kunnen veroorzaken. Deze doelstellingfunctie komt volgens sommige auteurs in de praktijk veel voor (Huisman, 1996; de Groot, 1997). Dit geeft aanleiding tot een voorkeur voor met putopties afgedekte aandelenbeleggingen. De belegging krijgt in een bepaald opzicht dan toch nog iets obligatieachtigs waaraan vele beleggers in het verleden gewend zijn geraakt namelijk de (nagenoeg 100\%) veiligstelling van de hoofdsom. De overgang van vastrentende beleggingen naar aandelenbeleggingen wordt erdoor vergemakkelijkt. Dit wil zeggen dat deze beleggers in voorkomende gevallen eerder streven naar een gegaran- 
deerde minimumrentabiliteit dan naar een optimale mean/variance-combinatie volgens de klassieke beleggingstheorie. Dit is precies wat Escape de beleggers biedt. Mogelijk gaat het hierbij om een andere risicomaatstaf bijvoorbeeld het reeds in 1952 door A. Roy gelanceerde 'safety first'beginsel of het in 1963 door Baumol gepresenteerde 'Expected Gain-Confidence Limit'-criterium. Baumol achtte de variantie überhaupt ongeschikt als risicomaatstaf (Baumol, 1952).

\section{f Relatief lage rente}

Beleggers die traditioneel beleggen op de vastrentende markten (zoals in deposito's en obligaties) zullen ceteris paribus eerder geneigd zijn gegarandeerde aandelenbeleggingen te kopen als de rente op vastrentende beleggingen laag is. De onvrede over het lage rendement drijft hen des te sneller in de armen van de innovatieve marktpartijen die hen een perspectief kunnen bieden op hoge verwachte aandelenrendementen onder andere (maar niet alleen) juist vanwege de lage rente! Gegarandeerde beleggingsproducten zullen het dus goed doen in perioden met lage rente en veel minder goed in perioden met hoge rente.

$g$ Hoog gerealiseerd aandelenrendement De kans bestaat dat kleine beleggers op het hoogste punt van de markt dreigen in te stappen. Vooral als men in het recente verleden hoge rendementen op de aandelenmarkt heeft gemist, is de kans groter dat men de overstap naar de aandelenmarkt alsnog wil maken. De impliciet aanwezige putoptie van Escape geeft dan bescherming.

\section{Samenvatting}

Het klassieke model voor de beoordeling van nieuwe financiële producten is te mager opgetuigd en is daardoor niet in staat om het ontstaan van financiële innovaties als het product Escape te verklaren. Een van de cruciale veronderstellingen in deze modellen is dat het gemiddelde en de variantie de allocatie van het te beleggen geld volledig determineren ongeacht al lang bekende bezwaren tegen de variantie als risicomaatstaf. Verder wordt verondersteld dat financiële markten worden gekenmerkt door marktperfectie. Om beide redenen missen deze modellen de aansluiting met de werkelijkheid.

Vertaald naar producten als Escape betekent dit dat deze producten wel degelijk toegevoegde waarde bezitten in de mate dat zij op een meer aansprekend risicobegrip van de beleggers inspelen en in de mate dat zij in een concurrerend

Tabel 1: Overzicht van mogelijke verklaringen voor de belangstelling voor de nieuwe complexe beleggingsproducten in de retailmarkt

1 Besparing op informatiekosten

2 Behalen van voordelen via de intermediair:

a schaalvoordelen

- deskundigheid

- transactiekosten

- markttoegankelijkheid

$\mathrm{b}$ fiscale voordelen

c risicoreductie

- als gevolg van regulering financiële industrie

- als gevolg van portefeuillevorming

3 Besparing op sociaal-psychologische kosten

4 Zeer sterke risicoafkeer (myopisch gedrag):

(verwerping van de variantie als risicomaatstaf en daarmee van het mean/variancemodel a la Markowitz)

5 Alleen neerwaarts risico telt

6 Lage rentestand (deposito's en obligaties)

7 In recente verleden gemiste hoge aandelenrendementen op aandelen 
aanbiedingsklimaat bijdragen aan het opheffen van een of meerdere bestaande marktimperfecties voor bepaalde groepen van beleggers. Tabel 1 op pagina 359 geeft een samenvattend overzicht van imperfecties.

Ook te oordelen naar de successen van de nieuwe beleggingsproducten als Escape en zijn vele nakomelingen - inmiddels zijn miljarden guldens langs deze weg belegd waarbij de zogenaamde 'click-fondsen' een extra grote bekendheid hebben gekregen - lijkt het aannemelijk dat deze fondsen voorzien in een reële maatschappelijke behoefte, gegeven het bestaande institutionele en fiscale kader.

De 'Escape'-kopers van het eerste uur zullen bepaald geen spijt hebben van de stap die zij sinds 28 december 1995 hebben gezet van een gemiddeld ongeveer $3 \%$ rentedragend deposito naar een qua marktrisico neerwaarts afgegrendeld aandelenproduct met een rendement van bijna $60 \%$ in de hoogtijdagen van de Amsterdamse effectenbeurs in het voorjaar van 1997.

\section{I T E R A T U U R}

Benartzi, S. en R.H. Thaler, (1993), Myopic loss aversion and the equity premium puzzle, (geciteerd in Vorst, 1995).

Baumol, W.J., (1963), An Expected Gain-Confidence Limit Criterion for Portfolio Selection, Management Science 10, October 1963.

Bongartz-Renaud, Douglas, (1993), 'Nieuwe generatie'-opties, Financiële Instrumenten (Moderne vormen van financiering en risicobeheersing), redactie P.J.W. Duffhues, J.G. Groeneveld, J. van der Hilst, i.h.b. par.3.2., Kluwer Bedrijfswetenschappen, tweede druk.

Duffhues, P.J.W., (1993), Ontstaan, rubricering en functies van financiële innovaties, Financiële Instrumenten (Moderne vormen van financiering en risicobeheersing), Hfdst 1 , (Kluwer).

Duffhues, P.J.W.. (1996), De Escape: sparen of beleggen?, Economisch Statistische Berichten, 21 februari.

Groot, J.S. de, (1997), Beleggers willen garantieproducten, Risico \& Rendement (Compendium voor financiële markten), Redactie L.A. Ankum, P.J.W. Duffhues, C.J.C.M. Hendriks en J.J. Roes, aflevering 10, april, Kluwer.

Hasselt, P. van, (1996), Exotische opties: het 'geheim' van Centraal Beheer, Economisch Statistische Berichten, 31 januari 1996.
Hendriks, C.J.G.M., (1995), Alternatieven van directe beleggingen in aandelen, Risico \& Rendement (Compendium voor financiële markten), redactie L.A. Ankum, P.J.W. Duffhues, C.J.G.M. Hendriks en J.J.R. Roes, april.

Horne, James C. van, (1985), Of Financial Innovations and Excesses. The Journal of Finance, July.

Huisman, R., (1996), Nieuw leven voor 'safety first', Economisch Statistische Berichten, 29 mei, p. 493.

Hull, John C., (1993), Options, futures, and other derivative securities, Prentice-Hall International, second edition.

Korteweg, P., (1994), Fiscus omhelst verzekeraars, Bank-en Effectenbedriif, oktober.

Levy, Haim, en Marshall Sarnat, (1972), Investment and Portfolio Analysis, Wiley \& Sons.

Pontier, J.H., (1995), Escape, nieuwe naam voor oeroude optiecombinatie, Het Financieele Dagblad, 23 december.

Romyn, M., (1995), 'Escape', een vlucht uit de fiscale werkelijkheid, Het Financieele Dagblad, 21 december.

Roy, A., (1952), Safety first and the holding of assets, Econometrica (geciteerd in Huisman, 1996).

Rubriek 'Economics Focus': Stay-at-home shareholders, The Economist, 17 februari 1996.

Silber, William L., (1983), The Process of Financial Innovation, The American Economic Review, May.

Shefrin, H.M. en M. Statman, (1993), Behavioral aspects of the design and marketing of financial products, Financial Management.

Verboven, A.H.F., en M.R.R. van Bremen, (1995), Escape: een belastbare én dure convertible, Het Financieele Dagblad. 22 december.

Vorst, A.C.F., (1995), De tijdshorizon van beleggers, Economisch Statistische Berichten, 4 januari.

Vorst, A.C.F., (1995a), Beleggen in een piramide, Economisch Statistische Berichten, 23 augustus.

\section{N O T E N}

1 Vergelijk Bongartz-Renaud (1993).

2 De fiscale aspecten van de Escape komen uitvoeriger aan bod in Duffhues (1996). Inmiddels heeft het Ministerie van Financiën in november 1996 besloten dat de vermogenswinsten vanaf dat moment op een in 'Escape 1.1' omgezette 'Escape'-beleggingen niet zullen worden belast voor particulieren. Over de resterende belastbaarheid van de vermogenswinst in het toen verstreken eerste bestaansjaar 1995/1996 is door de bemiddelende bank een juridisch proces aangekondigd. 